\title{
El proceso educativo desde el análisis de la economía de la población mundial ${ }^{*}$
}

\author{
Jackson Acosta Valdeleón ${ }^{* *}$ / Wilson Acosta Valdeleón***
}

Fecha de recepción: 13 de agosto de 2012

Fecha de revisión: 17 de septiembre de 2012

Fecha de aprobación: 22 de octubre de 2012

\section{Resumen}

El presente artículo trata de establecer conexiones entre las particularidades de la teoría económica en cada una de sus edades y las orientaciones que en correspondencia asume la educación para la productividad. Para ello acudimos a autores emblemáticos que fueron ampliamente difundidos durante los procesos de modernización adelantados por los países del Tercer Mundo a lo largo del siglo $X X$. Igualmente, se busca mostrar la forma en que los objetivos de crecimiento mercantil se tradujeron en propósitos formativos y criterios axiológicos basados en consideraciones economicistas.

Palabras clave: economía demográfica, productividad, sistema educativo, teoría económica, educación.

* Artículo de reflexión, fruto del trabajo investigativo adelantado en el Grupo Sociedad Educadora, reconocido por Colciencias.

** Doctor en Educación, Universidad Pedagógica Nacional e Investigador Fundación Sociedad Educadora. Autor de numerosos artículos sobre gestión de la educación, economía y formación del capital humano en Colombia. Correo electrónico: jacksonacostaval@gmail.com.

*** Doctor en Educación, Universidad Distrital, Docente Universidad de La Salle, Bogotá, Investigador principal del Grupo Historia de las Prácticas Pedagógicas en Colombia e investigador de la Fundación Sociedad Educadora. Correo electrónico: wilsonacosta30@ hotmail.com 


\title{
The educational process from the analysis of the economy of the world population
}

\begin{abstract}
This paper seeks to establish connections between the particularities of economic theory in each of its ages and the paths that, correspondingly, education assumes to encourage productivity. Therefore, we turn to emblematic authors that were widely distributed during the modernization processes carried out in Third World countries in the twentieth century. Likewise, we seek to show how commercial growth objectives resulted in educational purposes and axiological criteria based on economistic considerations.
\end{abstract}

Keywords: demographic economics, productivity, education system, economic theory, education.

\section{O processo educativo a partir da análise da economia da população mundial}

\section{Resumo}

O presente artigo tenta estabelecer conexões entre as particularidades da teoria econômica segundo as diversas idades e as orientações que em correspondência assumea educação para a produtividade. Para isso recorrem à autores emblemáticos que foram amplamente divulgados durante o processo de modernização feitos pelos países do Terceiro Mundo durante o século XX. Da mesma forma, procuram mostrar a forma em que os objetivos de crescimento mercantil foram traducidos en propósitos fomativos e critérios axiológicos baseados em considerações economicistas.

Palavras-chave: economia demográfica, produtividade, sistema educativo, teoria económica, educação. 


\section{Introducción}

Según Ekelund y Hébert (1992), uno de los desarrollos más importantes del análisis económico del siglo $X X$ fue el resurgimiento del interés de los economistas por la economía agregada, "esto es, por la teoría macroeconómica y monetaria". (Ekelund y Hébert, 1992, p. 672). La primera es la continuación de la preocupación de la Statistik (Ciencia del Estado) de finales del siglo XVIII por constituir la población en un instrumento de poder alternativo a la milicia. Los gobiernos ven que sus habitantes son susceptibles no solo de ser gobernados y gravados, sino que intuyen la posibilidad de estimular sus potencias para hacerlos productivos. El segundo interés surge con la necesidad de encontrar otros medios de enriquecimiento, sin recurrir a las escasas reservas de metales preciosos que al soportar la emisión de moneda no permitían la expansión de los mercados, ni a las escasas tierras disponibles cuya sobre especulación las convertía en prendas comerciales evitando su labranza.

La población humana, como la única especie capaz de producir trabajo y consumir racionalmente productos del trabajo, se convertirá en tema fundamental para los economistas que buscan establecer relaciones más eficientes entre la producción de mercancías y su consumo a nivel global. A lo largo de dos siglos, el Estado verá a la educación como un medio de progreso, fomento o desarrollo productivo, que transforma los comportamientos espontáneos de los individuos en hábitos productivos necesarios para asegurar el bienestar nacional.
A continuación mostramos a través de cinco autores emblemáticos, ampliamente difundidos durante los procesos de modernización adelantados en el Tercer Mundo, algunas correspondencias entre los presupuestos de la economía de la población y la forma en que son traducidos en propósitos educativos.

\section{Smith: división del trabajo y de la labor intelectual}

Para la teoría clásica, la riqueza es el resultado de la producción de valores creados mediante el trabajo. A su vez, reconoce que el trabajo puede maximizarse mediante la utilización de Bienes de Capital como mecanismos, máquinas, herramientas o instrumentos, que posibilitan la generación de ganancias superiores a las necesarias para mantener la fuerza laboral ${ }^{1}$.

Adam Smith concluyó que la maximización de la utilidad del trabajador se logra por la división del trabajo, asimismo atribuía el enriquecimiento de naciones como Gran Bretaña y Francia a una especialización de las actividades verificada en los talleres de finales del siglo XVII. En algún momento dichos talleres habían alcanzado tal demanda que requirieron el exhaustivo empleo de obreros inexpertos que no podían seguirse adiestrando en la díada aprendiz-oficial.

1 Marx y otros autores socialistas aceptaban esta visión clásica del capital, pero consideraban que solo podían ser considerados como capital los bienes productivos que permitían obtener ingresos independientemente del trabajo realizado por su dueño. En consecuencia, defendían que el capital representado en medios de producción debería ser únicamente propiedad del Estado y no de un grupo minoritario de personas (Althusser, 1972). 
De otro lado, era necesario facilitar la convivencia productiva en medio del hacinamiento que caracterizó desde sus comienzos el modelo fabril, y complejizar las formas contables creadas en el auge mercantil del siglo XVI. Se configuran rudimentarias estrategias de planeación que permiten establecer diversos grados de utilidad, necesidad y beneficio en los distintos trabajos y, en correspondencia, crear un sistema preciso para la asignación de salarios. Para Smith esta es la diferencia fundamental entre los países adelantados y los que permanecen en la barbarie:

En todas las demás manufacturas y artes los efectos de la división del trabajo son muy semejantes a los de este oficio poco complicado, aun cuando en muchas de ellas el trabajo no puede ser objeto de semejante subdivisión ni reducirse a una tal simplicidad de operación. Sin embargo, ja división del trabajo, en cuanto puede ser aplicada, ocasiona en todo arte un aumento proporcional en las facultades productivas del trabajo. Parece que la separación de los distintos oficios y actividades entre si debióse a las consecuencias de esta ventaja. Por lo general, esta separación es llevada al máximo en aquellos países que gozan del más alto grado de actividad y de adelanto; lo que en una sociedad que se halla en la barbarie es tarea de un solo hombre, suele corresponder a varios en una sociedad adelantada (Smith, 1982, p. 10).

Para Smith la división del trabajo además de ser un fin productivo tenía el atributo moral de evitar que los hombres ocuparan su tiempo en actividades ociosas y concentrar su atención en el trabajo vigoroso. Para este economista, los hombres, a menos que se le consigne a una labor constante y repetitiva, nunca adquieren hábitos de trabajo ni responsabilidad, lo cual es especialmente evidente en los muchachos:

Lo corriente es que el hombre haraganee un poco al llevar sus manos de una actividad a otra distinta. Es raro que empiece el trabajo con interés vivo y entusiasta; suelen decir que no les apetece y durante algún tiempo se entretienen sin poner toda el alma a producir. La costumbre de remolonear y de aplicarse al trabajo con descuido indolente, que adquieren de una manera natural, o mejor dicho, forzosamente, todos los trabajadores del campo que se ven obligados a cambiar de tarea y de herramientas cada media hora, y a emplear sus manos de veinte maneras distintas casi todos los días de su vida, los vuelve casi siempre haraganes, perezosos e incapaces de ningún esfuerzo vigoroso hasta en las ocasiones más apremiantes. Por tanto, $y$ con independencia de sus fallos en cuanto a destreza, basta esta sola causa para reducir siempre de una manera considerable la cantidad de obra que ese operario es capaz de realizar (Smith, 1982, p. 13).

El trabajo especializado también avivaba el ingenio del hombre, lo que suponía la contribución intelectual de los obreros a la riqueza de sus naciones. Cada uno de ellos podía reflexionar, entre otras cosas, acerca de la manera de suprimir y abreviar los procesos productivos; descubrir tratamientos químicos y mecánicos más eficaces; y adoptar formas de organización más fructíferas. Todo esto conduciría a dilatar el comercio del continente y mejorar las condiciones de vida de todos sus habitantes. Para Smith tales innovaciones se harían más frecuentes cuantos más obreros especializados hubiese; la familiaridad con el trabajo, el producto de su trabajo y las condiciones de producción era un elemento insustituible para lograr una mayor eficacia en las fábricas. 
Es mucho más probable que los hombres descubran métodos más fáciles y rápidos de alcanzar un objetivo cualquiera cuando tienen concentrada por completo su atención en aquel, que no cuando esa atención se dispersa en una gran variedad de cosas. Ahora bien: como consecuencia de la división del trabajo, toda la atención de cada hombre se encuentra naturalmente dirigida hacia algún objetivo único y muy sencillo. De ahí que sea natural esperar que uno $u$ otro de los hombres empleados en cada operación específica del trabajo descubra pronto métodos más fáciles y rápidos de realizar esta tarea suya especial, siempre que la índole de la misma sea susceptible de ello (Smith, 1982, p. 13).

Debe aclararse que Smith no propuso una capacitación procedimental extendida a los obreros para estimular la innovación en la fábrica, por el contrario, reconocía que la actividad intelectual estaba reservada a cierto número de afortunados, una clase especial de personas que por sus aptitudes o por las condiciones en que los había colocado la naturaleza, tenían la facilidad de idear procesos y crear máquinas para mejorar las condiciones de producción existentes. El ingenio de un obrero puede ser considerado un aporte técnico y no un descubrimiento científico.

La filosofía o teorización, al igual que todas las demás actividades, llega a convertirse a medida que la sociedad progresa, en profesión principal única y en tarea concreta de una clase especial de ciudadanos. Al igual, también, de todas las demás actividades, esta profesión se subdivide en un gran número de ramas distintas, cada una de las cuales proporciona tarea a una casta o clase especial de pensadores; y ocurre que esta subdivisión de actividades aumenta la capacidad y ahorro de tiempo en el pensar, lo mismo que en cualquier otra actividad. Cada individuo llega de ese modo a ser más experto en su propia rama de actuación, se consigue en conjunto una cantidad mayor de obra, y con ello un considerable aumento en el acerbo total de conocimientos (Smith, 1982, p. 14).

\section{Marx: educación técnica y control obrero}

Casi un siglo después de que Smith publicara La riqueza de las naciones (1776), Marx introduce el concepto de Fuerza de trabajo para definir el papel de la población en el proceso de producción. En su tratado sobre El capital (1867) Marx reconoce que casi todas las personas tienen la posibilidad de invertir sus capacidades intelectuales y físicas en la obtención de un producto; y a mayor inversión de capacidades, mayor incremento en el valor de la mercancía final.

Marx considera que la fuerza de trabajo puede ser comprada y vendida como mercancía, para regular sin diferenciar niveles cualitativos 0 cuantitativos entre sus diversos poseedores. Incluso, al convertirse en mercancía puede realizarse con ella transacciones parciales sin requerir la dedicación exclusiva de una persona; en otras palabras, "el uso de esta fuerza de trabajo le pertenece, pues, durante un día, como el de un caballo que se alquila diariamente" (Marx, 1981, p. 49).

La determinación del precio de esta "mercancía" en su estado natural es el mismo para todos, se considera que una persona en condiciones de 
salud aceptables y sin impedimentos físicos o mentales puede lograr niveles elementales de destreza en muy poco tiempo. Por lo anterior, la determinación de su precio se calcula en razón del tiempo de utilización, el desgaste inherente al trabajo desarrollado y la inversión del esfuerzo como especie:

Como cualquier otra mercancía, la fuerza de trabajo posee un valor determinado por el tiempo de trabajo necesario para su producción [...] La fuerza de trabajo, pues, tiene exactamente el valor de los medios de subsistencia necesarios al que la pone en acción, para que pueda comenzar al día siguiente con iguales condiciones de vigor y salud (Marx, 1981, p. 42).

Pese a estas restricciones que impedían la determinación de las capacidades individuales de los empleados, se consideraba que el rendimiento y el ritmo de producción de un trabajador durante una jornada fija se podían aumentar por diversos medios.

El primero y principal de ellos era la introducción de la planificación manufacturera; así, el "trabajador traspasa los límites de su individualidad, y desarrolla su potencia como especie [...] obrando simultáneamente con otros para un fin común" (Marx, 1981, p. 82). Y al coordinar estratégicamente las labores "la cooperación aumenta considerablemente el valor y la cantidad de los medios de producción, materias primas e instrumentos de trabajo" (Marx, 1981, p. 88).

El segundo, retomando la idea de Smith, era permitir que un trabajador se especializara de modo que "su habilidad adquiera la forma más adecuada para [el] ejercicio circunscrito". Esta especialización tenía una ventaja adicional: en muchos casos se vinculaba a los niños desde tempranas edades en los talleres de manufactura, de tal manera que la habilidad de sus padres y los secretos de los oficios pudieran ser transmitidos sin requerir la inversión en instrucción por parte del capitalista. Para Marx (1981):

Cuando se repite constantemente un acto simple y se concentra en él la atención, se llega a alcanzar por la experiencia el efecto útil deseado con el menor gasto posible de fuerza, y como siempre diversas generaciones de obreros viven y trabajan al mismo tiempo en los mismos talleres, los procedimientos técnicos adquiridos, las llamadas tretas del oficio, se acumulan se transmiten, aumentándose así la potencia productora del trabajo (p. 88).

La tercera forma de maximizar el esfuerzo en el proceso productivo es mediante el empleo de máquinas. Estas superan las limitaciones del organismo humano multiplicando su potencia productiva, por ejemplo, "si solo posee dos manos para tener agujas, la máquina de hacer medias, movida por un hombre, hace puntos con muchos millares de agujas". Al adquirir dominio en ciertos oficios cada vez más tecnificados, el trabajo del obrero será determinante para la disminución de los costes de manufactura y el aumento de la producción. Para Marx, esta entrada del obrero en el juego de la determinación de precios resulta una ficha clave para la conquista de mejores condiciones de vida por parte del proletariado.

En la medida que el obrero reconociera su importancia dentro del proceso productivo y lograra obtener "el conocimiento objetivo de las leyes de la producción", el dominio de la clase 
burguesa se debilitaría. Por lo tanto, una buena educación para Marx debería estar centrada, además de la enseñanza de los principios de la producción, en la instrucción que favoreciera el desarrollo de las destrezas necesarias para el manejo de las máquinas; elemento indispensable cuando se obtuviera "la inevitable conquista del poder político por la clase obrera". En palabras del autor:

En la educación del porvenir, el trabajo manual productivo irá asociado a la instrucción y a la gimnasia para todos los jóvenes de ambos sexos que pasen de cierta edad, y a los ejercicios militares para los varones. Tal es el único método para formar seres humanos completos (Marx, 1981, p. 118).

\section{Marshall: la abstinencia como habilitador de la participación}

A comienzos del siglo $X X$, el predominio de la concepción del trabajo como determinante del valor se vio desplazada rápidamente por los economistas neoclásicos, quienes identificaron en la utilidad (sujeta a la oferta y por lo tanto a niveles de satisfacción o insatisfacción relativos) la esencia del valor. De esta forma "el sistema económico quedó irremediablemente identificado con el mercado y la investigación económica con las condiciones de mercado (los precios) bajo los cuales sucede el intercambio" (Escobar, 1996, p. 133).

Marshall (1948) afirmaba que las mejoras significativas en la producción dependían de la capacidad para superar los viejos temores de la teoría maltusiana y los presupuestos de la "ciencia lúgubre"2 respecto al crecimiento demográfico. En este punto, la educación se convierte en un punto central de la expansión productiva, animando a las personas a entrar en el juego del capitalismo, cuyas probabilidades de ganar son proporcionales a la cantidad de valores que se apuesten.

El primer paso era garantizar un tipo de educación centrada en la enseñanza de las técnicas y procedimientos utilizados en las fábricas. Podía conducir al individuo a asumir un actitud reflexiva acerca de la efectividad de los diversos procesos implementados en estas y a largo plazo desarrollaría en él la capacidad para realizar razonamientos sobre la eficiencia y la disposición de los diversos elementos productivos, a través de un análisis empírico. Esta sofisticación de su análisis técnico le permitiría competir ventajosamente con las industrias en las cuales había trabajado.

También era necesario trasmitir a las futuras masas trabajadoras los conocimientos que habían conducido a los países ricos en sus primeras etapas de industrialización. La inversión en la educación técnica era la clave para lograr no solo una mejora sustancial en la economía sino un ideal nacional. Para Marshall (1948):

Una buena educación proporciona grandes beneficios indirectos, incluso al trabajador ordinario: estimula su actividad mental, introduce en él la costumbre de investigar las cosas, le eleva el tono de su vida tanto en las horas de trabajo como fuera de él; es,

2 La teoría de Malthus, conocida también con el nombre de "ciencia lúgubre", reconocía el papel de las plagas, guerras y epidemias en la contención de la superpoblación, además sugería estrategias morales como el matrimonio tardío y la formación de familias pequeñas (Malthus, 1951). 
pues, un medio importante para la producción de riqueza material, al propio tiempo que, considerada como un fin en sí misma, no es menos importante que los demás fines que puedan servir a la producción de riqueza material (p. 179).

El segundo paso era garantizar salarios más allá de la regeneración de energías vitales, que permitieran a las personas ahorrar módicas sumas para emprender negocios individuales. Los teóricos de la abstinencia concordaban en la posibilidad de rendimientos futuros como incentivo para el ahorro en el consumo, con el fin de utilizar parte de los ingresos en el aumento de la producción. También coincidían con los clásicos en que las ganancias resultantes del aumento de capital utilizado en el proceso productivo aumentaban en relación directa con la capacidad de las naciones para asegurarse una producción continua de bienes de capital (maquinaria). Como la producción de máquinas y de otros bienes de capital como hornos de fundición, ferrocarriles y represas necesitan de una gran cantidad de ahorro, se esperaba que la abstinencia de los ciudadanos rindiera mayores dividendos, en tanto más grande fuera su capacidad de acumulación.

Culminados estos dos pasos, se entra en un periodo en el que todos los individuos que componen la población nacional entran en un sistema que expande sus mercados mediante la iniciativa y la especulación individual.

Marshall, al igual que la mayoría de los economistas neoclásicos, difiere de la teoría convencional, en cuanto no considera el descubrimiento ni la invención como un producto exclusivo de aquellos que tienen posibilidades para dedicarse a un ejercicio reflexivo de tiempo completo. Más bien, considera que los mayores adelantos en la industria requieren que todas las personas generen el talento para innovar los procesos productivos; como no se puede saber quién producirá un descubrimiento significativo, debe darse educación técnica al mayor número de personas para aumentar tal probabilidad. En palabras de Marshall (1948):

Podemos, por tanto, concluir que la conveniencia de invertir fondos públicos y privados en la educación no debe medirse por sus frutos directos. Esa inversión será provechosa como tal para dar a las masas del pueblo mayores oportunidades que aquellas de que disponen generalmente, pues por ese medio, muchos que de otro modo habrían muerto sin darse a conocer pueden, por ese medio, conseguir el punto de partida necesario para desarrollar sus aptitudes innatas (p. 182).

La simple oportunidad de inventar una máquina o de facilitar un procedimiento ya era justificación para extender la enseñanza técnica a todas las personas de una ciudad. El aprendizaje orientado a elevar los volúmenes de conocimientos prácticos debía estar en consonancia con la educación "liberal" para superar

el estrecho alcance de la educación dada en la antigua escuela de humanidades de la clase media [...] perjudicial al progreso industrial "y permitir al maestro" inducir a sus alumnos a utilizar su mente para algo más elevado que la adquisición de conocimientos (Marshall, 1948, p. 178).

Estas características hicieron de este tipo de enseñanza una estrategia adecuada para introducir los oficios en la escuela, lo cual ayudaría a emular a cierto tipo de empresarios que 
como "los ingleses y, en grado todavía mayor, los norteamericanos habían desarrollado una habilidad especial para el conocimiento empírico". Para Marshall (1948): estos últimos habían adquirido de los negocios la facultad de rechazar lo intrincado en la maquinaria y en los procedimientos, por no valer lo que cuesta, y esta especie de instinto práctico les [permitió] muchas veces tener éxito en la competencia con rivales de otros países del continente que son mucho más instruidos (p. 177).

El último fundamento de esta estrategia educativa era su carácter no clasista: los conocimientos relativos al funcionamiento de la empresa deberían impartirse indistintamente a las masas trabajadoras y a los ricos. En el caso de los primeros, les prepararía para el trabajo arduo en las fábricas y los familiarizaría con las posibilidades que brindaba el sistema liberalista y la propiedad privada; y en el caso de los ricos les ayudaría a conocer más de cerca las industrias que heredarían. En muchos casos Marshall enalteció la decisión de algunos burgueses de enviar a sus hijos a trabajar dentro de sus mismas fábricas como un seguro contra la inexperiencia. Enfatizaba el hecho de que la educación tradicional solamente proporcionaba al niño una lejana idea de los procesos industriales, y por lo tanto de las habilidades relativas al dominio de estos. Por tal motivo, recomendaba que junto a los rudimentos de lectura y escritura existieran actividades de tipo práctico; las cosas que se debieran aprender para la vida estarían esperando a ser aprendidas de forma espontánea. En la medida en que se tuviese más contacto con diferentes tipos de trabajos y labores, el estudiante ampliaría su universo cultural. Marshall (1948) resume esta idea de la siguiente forma:

Los conocimientos adquiridos en la escuela son importantes, no tanto por su valor en sí mismo como por la aptitud para ampliarlos que proporciona la educación escolar, ya que una buena enseñanza general capacita a la mente para emplear sus mejores facultades en el desarrollo de cualquier trabajo y a utilizar el esfuerzo como un medio de aumentar la cultura, aunque no se ocupa de los detalles correspondientes a las distintas profesiones, los cuales deja para la educación técnica (p. 176).

La formación para el ahorro y la inversión se convierten para los neoclásicos en elementos fundamentales para la expansión de los mercados. El sistema económico continuará su apacible crecimiento con el lento pero progresivo ritmo de la contratación y el ahorro, durante las tres primeras décadas del siglo XX. Por ahora resultaba conveniente no incomodarlo y revisar cualquier obstáculo que pudiera interponérsele.

\section{Keynes: la pasión de hacer dinero}

La década del treinta despierta con una crisis. Les esperaba a los economistas la tarea de infundir confianza en las inversiones y avivar nuevamente la fe en el sistema. Por su parte, la disciplina económica necesitaba reconstruirse y reevaluar la pertinencia de elementos como la intervención estatal en el crecimiento y control del mercado, y a la vez construir un nuevo edificio teórico que permitiese llegar a una teoría del equilibrio en medio de una crisis de recesión. 
Jhon Mainard Keynes, en su Teoría general sobre el empleo, el interés y el dinero (1936), menciona que debían ser los gobiernos -los cuales hasta el momento se habían mantenido al margen de los procesos económicos- los encargados de dirigir los rumbos de la economía mediante intervenciones decididas a través de políticas que regularan la producción, la oferta y la demanda, al mismo tiempo que aseguraban el control de los mercados, especialmente el bursátil.

Para Keynes, la educación en este contexto debía ser un proceso donde el individuo adquiriera conciencia de su ser económico como parte de un macrosistema. La educación era la encargada de formar en el individuo hábitos y prácticas saludables para la economía de los países; el ahorro planificado a través de fondos estatales, la inversión prudente con expectativas razonables de rendimiento, la creación de industrias y empleos necesarios para el país y la capacitación para desarrollar estos últimos debidamente, debían constituir las bases de una cultura de la prosperidad común enseñada desde la escuela. Era necesario superar entonces todos los temores que había generado la recesión y permitir que desde pequeños los niños "jugaran" a hacer dinero y que le tomaran amor a este. En palabras de Keynes (1945) existían: "valiosas actividades humanas cuyo desarrollo exigen la existencia del estímulo de hacer dinero y la atmósfera de la propiedad privada de riqueza" (p. 358).

Este juego al que se refiere Keynes son las inversiones con cierto margen de riesgo que se practican en las sociedades liberales, donde la seguridad de la inversión es inversamente proporcional a la ganancia. Sin embargo, para que este juego rindiera sus frutos debía inspirarse en los individuos una "pasión" por la riqueza, de otro modo el juego no tendría el capital suficiente para hacerse atractivo.

\begin{abstract}
La tarea de transmutar la naturaleza humana no debe confundirse con la de manejarla; aunque en el estado ideal los hombres pueden haber sido enseñados, inspirados o educados de manera que no se interesen en tales apuestas, aún puede ser sensato y prudente para un estadista permitir que se practique el juego, bien que sujeto a reglas y limitaciones, hasta que el común de los hombres, o por lo menos una parte importante de la comunidad, se adhiera de hecho y fuertemente a la pasión de hacer dinero (Keynes, 1945, p. 359).
\end{abstract}

Para este economista, el juego de la riqueza debía ser accesible a todos. En el caso de las personas pobres, se contemplaba la posibilidad de realizar inversiones con modestas expectativas de ganancia, evitando así comprometer sumas significativas que los condujeran a sentidas carencias. En palabras de Keynes (1945):

Para estimular esas actividades e inclina-
ciones no es necesario que se practique el
juego con apuestas y riesgos tan grandes
como ahora. Apuestas y riesgos mucho
menores pueden servir para el caso, con
el mismo resultado tan pronto como los
jugadores se acostumbren a ellos (p. 359 ).

Para el caso de inversiones significativas, aconsejaba consignar el dinero a interés y dejar en manos de los expertos el manejo de los excedentes: 
La experiencia sugiere que, en las condiciones existentes, el ahorro por medio de instituciones y de fondos de reserva es más que adecuado, y las medidas tendientes a redistribuir los ingresos de una forma que tenga probabilidades de elevar el consumo pueden ser positivamente favorables al crecimiento del capital (Keynes, 1945, p. 357).

Con Keynes se inicia una nueva era en la que la intervención del Estado desplazará la teoría de los mecanismos de ajuste automático favoreciendo el establecimiento de gobiernos previsores, donde el objetivo fundamental será mantener el crecimiento de la demanda acorde con el aumento de la capacidad productiva de la economía.

\section{Becker: la posibilidad de considerar la población como recurso}

La preocupación por la acumulación de capital, dentro del análisis económico de finales de la década de los treinta y comienzos de los cuarenta, se convierte en el núcleo de los primeros intentos por aplicar una teoría del crecimiento lo suficientemente compleja como para involucrar a las naciones industrializadas de Norteamérica y Europa junto con las naciones de la periferia. Surge entonces un problema para los nuevos economistas a la hora de orientar todos los campos de la producción, a favor del crecimiento económico.

En primer lugar, para que un país crezca debe tener a su disposición cierta cantidad de recursos naturales y, en tal caso, a la mayoría de países tropicales podría aplicarse la nueva teoría del crecimiento. Pero ante el sueño de hacer una teoría totalizante para el Tercer Mundo, este requisito sería un limitante ya que en muchas naciones dichos recursos eran inexistentes, escasos o habían sido explotados hasta el agotamiento. Se hacía entonces necesario, para el desarrollo de una teoría global del desarrollo, basar el factor recurso en otro elemento cuya existencia estuviese asegurada en la mayor parte de las naciones pobres.

Una de las características más significativas de los países "atrasados" era su amplia base poblacional. Sin embargo, hasta el momento no se había contemplado la posibilidad de tomarla como una fuente de capital o riqueza, sino que era concebida como un factor marginal de la producción. Pronto se hizo evidente la necesidad de una teoría que incluyera a los individuos en el análisis de la formación de capital, pero no solamente en su función de "aportantes" de fuerza, sino como un recurso con verdadero potencial que pudiese desarrollarse bajo las mismas lógicas del análisis marginal del valor. Solo cuando estuvieran resueltos estos problemas de índole disciplinar se podría proceder a la construcción de una verdadera teoría para el crecimiento y la formación de capital para el mundo "subdesarrollado".

Tal vez el mayor aporte de la Escuela de Chicago al estudio de la formación del capital durante la década de los cuarenta, es la innovadora implementación del análisis macroeconómico ${ }^{3}$,

3 La microeconomía estudia el comportamiento del individuo en los procesos de producción y distribución. En el primer aspecto se estudia la distribución del ingreso de acuerdo con parámetros particulares como nivel de estudios, posicionamiento social, características biológicas, etc. Para el segundo caso se analiza la manera en que los gustos y pautas culturales definen la forma en que la persona satisface sus necesidades de consumo desde las más 
el cual permite superar escollos que habían impedido a la teoría económica convencional considerar a la población como un factor susceptible de ser mejorado individualmente en su capacidad productiva. Las innovadoras categorías del recurso humano y del capital humano permitieron superar tres obstáculos del análisis convencional para concebir a la población como fuente de riqueza.

En primer lugar, se concebía dentro de la economía tradicional que cualquier objeto podía generar riqueza en virtud de su utilidad, es decir, la capacidad de satisfacer necesidades humanas. Así, la población al ser depositaria absoluta del proceso productivo constituía un fin en sí misma dentro del análisis económico y, por lo tanto, bajo esta condición, no se podía hacer una distinción real entre el beneficio (cantidad de riqueza producida) y el beneficiario (consumidor de la riqueza). De esta manera y para simplificar el problema, en muchos casos se la consideraba como una forma de rendimiento marginal de la producción: se valuaba únicamente su capacidad física, de acuerdo con la concepción homogenizante sobre la fuerza de trabajo que establecieron los clásicos y que predominó en la teoría económica por más de un siglo.

básicas hasta las más sofisticadas. En concordancia, su campo de análisis se restringe al manejo doméstico de los ingresos, a la forma en que diversos mecanismos como la publicidad inciden en los hábitos de consumo y la forma en que los mercados equilibran la demanda sin el condicionamiento de un estado interventor (Ferguson, 2001). Sin embargo, no se puede hacer una distinción tajante entre microeconomía y macroeconomía, por ejemplo, Gary S. Becker sitúa a la familia como el centro del "proceso productivo doméstico", la cual determina la demanda de bienes y servicios dentro de una sociedad (microeconomía), a la vez que influye en ciertas decisiones sobre la empresa sobre qué y cuántos bienes y servicios producirán, y con qué combinación de factores productivos (macroeconomía).
Para superar este obstáculo, Becker (1982) propone su teoría de la Economía doméstica, la cual considera a la familia como una pequeña fábrica donde se "combinan bienes de capital, materias primas y trabajo, para limpiar, procrear y producir de otra manera mercancías útiles" (Becker, 1982, p. 496). Este análisis contemporáneo admite que la producción y el consumo de bienes se realizan de forma simultánea dentro de los hogares, siendo los padres los depositarios iniciales de una inversión sobre bienes de consumo, como son considerados a veces los niños. Estos últimos, a medida que van creciendo, se hacen cargo de los deberes de la casa para que otro miembro de la familia (usualmente la madre) pueda salir a trabajar. De esta forma, y bajo un modelo simplificado de producción e intercambio, los bienes de la casa se convierten en bienes de mercado y consumo doméstico, y las personas, incluyendo los niños, se convierten en productores casuales, aumentando su utilidad a medida que van creciendo.

La educación para el Tercer Mundo debía introducir en sus planes de estudio rudimentos sobre el cuidado de la infancia, y los principios básicos del comportamiento y la salud humana en las primeras etapas de vida. En el caso de las mujeres era necesario implementar cátedras de economía doméstica que permitieran organizar la vida conyugal como una empresa sostenible que se capitaliza en el tiempo.

En segundo lugar, para las teorías económicas convencionales, los bienes que gozaran de algún valor debían tener una oferta limitada. La idea de la sobrepoblación introducida por Malthus en su Ensayo sobre el principio de la población (1798) constituyó la base para los 
tratados demográficos de la escuela clásica: la población humana crecía en progresión geométrica mientras que los recursos, especialmente la producción agrícola, crecía solo en progresión aritmética, lo que afectaba el mecanismo económico de manera negativa. La cantidad de la población que iba en ascenso constante y a un ritmo incontrolado, oponía un tropiezo fundamental a la teoría económica del valor demográfico.

Becker (1997) coincidía con los clásicos en que una característica del valor de la mercancía era su escasez sin embargo, respecto a la preocupación de Malthus, consideraba que esta obedecía más a una circunstancia histórica que a un problema esencial de la economía:

Los economistas clásicos esperaban una respuesta mucho mayor en el tamaño de la familia por variaciones en los ingresos, porque utilizaban esencialmente el enfoque maltusiano, consideraban que un incremento en los ingresos por arriba del nivel de subsistencia reduciría la edad en que se casaban las parejas y quizás también inducirían a una disminución en la abstinencia de los matrimonios. El desarrollo y la difusión de métodos efectivos de control de natalidad reducen la necesidad de descansar en matrimonios tardíos y en la abstinencia para lograr este objetivo; ello explica en parte por qué no esperamos más que el tamaño de la familia responda en gran medida a un cambio en el ingreso (Becker, 1997, p. 203).

Las familias grandes serían características en las áreas rurales debido a la escasa difusión de los métodos de anticoncepción y a diversas pautas morales que favorecerían su conformación. También se debía tener en cuenta el menor coste de crianza de los hijos en lugares de producción agrícola. Elementos como la educación y el fomento a la urbanización actuarían como reguladores del crecimiento demográfico4:

\begin{abstract}
Observaciones empíricas confirman la esperada relación negativa entre el tamaño de la familia y el costo de los niños. Las familias son más grandes en las áreas rurales que en las urbanas, principalmente porque los niños son más baratos en las primeras: obviamente, los alimentos y la vivienda son más baratos, y los niños ayudan en las tareas agrícolas (Becker, 1997, p. 203).
\end{abstract}

Un propósito fundamental de la educación era la formación para una sexualidad que permitiera el desarrollo de un sistema liberal. Esto implicaba enseñar a planear el matrimonio y la llegada de los hijos durante las máximas etapas de productividad y establecer el número ideal de integrantes por familia, para no agotar las reservas de capital producidas en el incipiente proceso de urbanización adelantado en el Tercer Mundo.

Tercero, la población era considerada un elemento natural de carácter ilimitado y carente de valor como el aire y el agua, los cuales, no obstante, podían generar riqueza a través de su conversión en aire acondicionado o su conducción por medio de redes de acueducto. Sin embargo, los seres humanos después de concretadas las legislaciones liberales no podían ser sometidos a la trata ni al comercio; se suspendía

$4 \quad$ La vigencia de esta concepción economicista de la población se puede observar décadas después en las estrategias de planificación familiar para el Tercer Mundo. En el informe de la OIT, Hacia el Pleno empleo se recalca la pertinencia de la escolarización al asegurar que "la educación puede desempeñar un papel importante, especialmente en lo que se refiere a la modificación de actitudes respecto al tamaño de la familia" (OIT, 1970, p. 305). 
de esta forma una condición fundamental para la formación de la riqueza: la posibilidad de ser transferibles. Así que no era posible determinar su precio dentro de un mercado.

La noción de mercado laboral hace posible que se puedan establecer pautas para transferir, si no los hombres, sí sus capacidades de acuerdo con sus habilidades para el trabajo. Sin embargo, esto solo se puede hacer cuando los mecanismos de capacitación productiva dentro de una nación son lo suficientemente amplios y especializados. En una población no capacitada el mercado laboral sería poco organizado y diversificado debido a la escasa preparación; en consecuencia, la poca dinámica que adquiriera el aparato producción se vería frenada inmediatamente por la reducida cantidad de mercancías que entraban en el juego del intercambio.

En el caso de los países pobres era necesaria una amplia capacitación en la educación primaria para echar a andar los sistemas de oferta laboral y así tener la oportunidad de administrar la tendencia ocupacional. Dicha educación estará destinada a proporcionar mano de obra más versátil, abandonando formas tradicionales de preparación como la tradición familiar y la formación en oficios. De esta forma, los Estados, al tener el control sobre las regulaciones salariales, ya no se verían impedidos para modificar el flujo de la ocupación, lo cual resulta clave cuando se necesite desviar gran parte de la mano de obra hacia labores poco atractivas pero vitales para el desarrollo económico de los países $^{5}$. En palabras de Becker (1997):

$5 \quad$ La teoría de Keynes había funcionado muy bien durante la crisis económica de la década de los treinta. No obstante, para el caso de aquellos países que tenían la mayoría de
La teoría implica que las ocupaciones menos deseables tiene que pagar sueldos más altos para compensar lo desagradable. Cuando la inversión en capacitación se mantiene constante, los trabajos menos placenteros pagan más. Cuando la inversión difiere significativamente, sin embargo, esto ya no es cierto; por ejemplo, los médicos, los ingenieros y los carpinteros tienen mayores ingresos que los trabajadores no calificados, los trabajadores domésticos y los conserjes; y al menos los escritores y los analistas de problemas sociales coinciden en que las primeras son ocupaciones más placenteras. La relación positiva entre los ingresos y al cantidad invertida en educación y capacitación puede explicarse introduciendo el costo de capacitación, junto con las diferencias de oportunidades $y$ habilidad (p.219).

Por último, según las teorías convencionales, el valor económico de los objetos residía en estrecha relación con su capacidad para ser medible (ser mensurable). A este respecto, el obstáculo para la concepción de la población como un bien provenía de las constituciones liberales, las cuales habían dado el mismo estatuto a todos los hombres. Estos se consideraban iguales ante la ley y ante el Estado; a todos de manera igualitaria, se le reconocían derechos inherentes como la libertad de empresa y de culto, la libertad de asociación y la paridad ante la ley. De esta forma, los seres humanos no podían ser -al menos legalmente- medibles, pues, su categoría de ciudadanos igualitarios los homogenizaba a todos evitando diferencias.

su población dedicada a la agricultura de subsistencia, estos presupuestos no funcionaban muy bien. Las personas acostumbradas al "diario vivir" no se veían tentadas a ocuparse en trabajos desagradables por más dinero que se les pagase. Máxime cuando estos trabajos requerían cierto nivel de preparación (Cardoso y Faletto, 1978). 
Este obstáculo se supera al introducir un nuevo concepto de análisis: el tiempo vital. El tiempo de las personas y no su naturaleza pueden ser medibles; de esta forma, el valor del tiempo en que se desenvuelve la existencia de una persona puede cobrar más valor de acuerdo con el grado de desarrollo que tenga el país en donde habite.

No tiene el mismo costo el tiempo de una madre en los Estados Unidos que en Latinoamérica. Para Becker un buen ejemplo lo tiene la diferencia en el valor de la crianza de los niños en un país desarrollado y un país pobre. El tiempo invertido en un niño es un tiempo no remunerado, y por lo tanto, se puede cuantificar por el dinero que se deja de devengar en cierto tiempo, resultando que la crianza de un niño en un país desarrollado es más valiosa que en un país pobre:

El valor del tiempo que gastan los padres, principalmente las madres, es un costo importante de criar niños, y las mujeres tienden a tener pocos niños cuando su tiempo tiene un alto valor. Los incrementos en la educación en los Estados Unidos y en otras partes parecen haber reducido el tamaño de la familia (Becker, 1997, p. 203).

\section{Conclusiones}

Para los economistas clásicos, el proceso "calificatorio" no se restringía a la enseñanza dentro de la escuela, considerándose aspectos como la pericia y el aprendizaje dentro de los gremios la verdadera médula del desempeño laboral. Tampoco contemplaron la diferenciación salarial como un elemento significativo dentro del proceso de industrialización que pretendían llevar a cabo las metrópolis en su frenética carrera por dominar los mercados internacionales.

El problema de la educación planteado desde la escuela neoclásica se refería básicamente al papel de la población en el proceso productivo. En ellas se tratan tres problemas fundamentales: el primero, la inversión estatal en relación con el aumento demográfico y las responsabilidades contractuales de los gobiernos para con ella. Segundo, la ampliación de la educación técnica dentro de las naciones industrializadas orientada a la especialización de los individuos en diversos procesos productivos. Y tercero, la contribución de la población a los procesos de crecimiento, en especial los de industrialización, bien sea a través del ahorro o la actitud empresarial ${ }^{6}$.

Estos tres aspectos determinaran los propósitos de la formación en oficios, la cual fue la principal práctica educativa para las masas en los países tempranamente industrializados durante la segunda mitad del siglo XIX y las primeras décadas del siglo XX. Sin embargo, la adecuación de este tipo de enseñanza en países de la periferia supondrá para los expertos economistas la superación de diversos obstáculos de tipo teórico, debido a las disímiles condiciones de producción que se presentaban entre unos y otros.

Con la introducción de la concepción de Capital humano en el campo educativo se opera en esta

6 Joseph Schumpeter rescata de Walras la noción de empresario identificándolo como un agente activo del progreso económico y no solamente como un factor marginal del proceso productivo. Esta misma preocupación por la formación de empresarios se encontrará décadas después dentro de programas adelantados bajo la consigna del desarrollo (Escobar, 1996, p. 299). 
una fuerte simplificación impuesta por la teoría económica. La teoría sobre la formación del capital reconoció durante muchas décadas la imposibilidad de considerar a la población como un recurso susceptible de ser desarrollado e intercambiado. Es solamente después de la década de los cuarenta, cuando estos obstáculos podrán ser superados mediante la introducción del análisis microeconómico al estudio de las poblaciones nacionales. En adelante, la nueva concepción del ser humano como recurso será el fundamento de todas las políticas para el tratamiento de la población en el Tercer Mundo y un elemento fundamental en la planeación del crecimiento en las naciones pobres.

Así, dentro de su análisis, la educación puede constituirse en un sistema de calificación de mano de obra que luego es empleada o bien puede identificarse como un mecanismo regulador de la diferenciación salarial y por ende de cuestiones referentes al funcionamiento del mercado. En todo caso, queda claro que para las décadas de los cincuenta, los sesenta y los setenta la educación ha abandonado (esta vez convertida en un derecho garantizado por el Estado), los ideales formativos de la primera mitad de siglo, involucrando a todos los sectores de la sociedad en un único y universal sentido: el desarrollo productivo.

\section{Referencias}

Althusser, L. (1972). Para leer el Capital. Madrid: Alianza Editorial.

Becker, G. (1997). Teoría Económica. México: Fondo de Cultura Económica.
Cardoso, F. y Faletto, E. (1978). Dependencia y desarrollo en América Latina: Ensayo de interpretación sociológica. México: Siglo XXI Editores.

Ekelund, R. y Hébert, R. (1992). Historia de la economía y de su método. Madrid. McGraw-Hill.

Escobar, A. (1996). La invención del Tercer Mundo: construcción y deconstrucción del desarrollo. Bogotá: Grupo Editorial Norma.

Ferguson, J. (2001). Historia de la economía. México: Fondo de Cultura Económica.

Keynes, J. (1945). Teoría general de la ocupación, el interés y el dinero. México: Fondo de Cultura Económica.

Malthus, T. (1951). Ensayo sobre el principio de la población. México: Fondo de Cultura Económica.

Marshall, A. (1948). Principios de economía. Madrid: Aguilar.

Marx, C. (1981). El capital: desarrollo de la producción Capitalista. México: Editores Mexicanos Unidos.

OIT (1970). Hacia el pleno empleo: un programa para Colombia. Bogotá: Banco de la Republica.

Smith, A. (1982). Investigación sobre la naturaleza y causas de la riqueza de las naciones. México: Fondo de Cultura Económica. 